\title{
Entrevista
}




\section{Faculdade de Filosofia da USP: lições inesquecíveis}

$\mathrm{D}$ eslumbramento - essa era a impressão dos que ingressaram na Faculdade de Filosofia, Ciências e Letras - FFCL - há mais de meio século. Porque nela se adotavam métodos de ensino vigentes na Europa, que conduziam os alunos a se tornarem pesquisadores. Deslumbramento porque os estudantes conviviam e aprendiam com professores estrangeiros de renome internacional. $\mathrm{E}$ também com notáveis mestres brasileiros, como André Dreyfus. Para recolher essa -memória, Marco Antonio Coelho entrevistou três professores de áreas das ciências biológicas - Crodowaldo Pavan, Antonio Brito da Cunha e Erasmo Garcia Mendes (entrevista que prosseguirá com outros professores das áreas de Física, Química e das ciências humanas).

A recuperação dessa memória não é por nostalgia. É pela procura de lições distantes no tempo mas que podem ser ainda válidas, embora hoje os problemas sejam de outras dimensōes numa universidade no limiar de outro século.

Estudos Avançados: Como avalia a criação da USP e de sua Faculdade de Filosofia no panorama da evolução cultural e científica do Brasil?

Crodowaldo Pavan: Para início de conversa, dou ênfase especial ao fato de a fundaçáo de escolas superiores e universidades no Brasil ter acontecido muito tempo depois da criação de universidades e escolas superiores em outros países da América Latina, como no Peru. É certo que nas épocas de D. João VI e de Pedro II, como nos primórdios da República, houve vontade de se organizar universidades no País, mas de positivo nada aconteceu, além da instalação de meia-dúzia de escolas superiores, algumas das quais realmente importantes.

Outra coisa surpreendente, ao meu ver, é que, a despeito de o Rio de Janeiro ter sido a Capital Federal, foi em São Paulo que se deu o passo inicial para se ter no Brasil uma verdadeira universidade. Como é sabido, isso se deveu a Júlio de Mesquita Filho, ao jornal $O$ Estado de $S$. Paulo e a Armando Salles de Oliveira. Assim, apesar desse atraso - face 
ao sucedido em outros países latino-americanos - tivemos a oportunidade de nos destacar e de sobressair com relaçáo aos países vizinhos. Houve um tempo em que a Argentina estava em nível melhor do que o nosso, mas, por razões políticas e outras, ela regrediu.

A pergunta que deve ser feita é: por que começou em São Paulo? $\mathrm{Na}$ realidade houve um interesse acentuado de $O$ Estado de $S$. Paulo, jornal que habitualmente reunia em sua redação - na rua Boa Vista um grupo importante de intelectuais, os quais freqüentemente debatiam os problemas da educação no Brasil. Nessas reuniōes, em que participavam Júlio de Mesquita Filho, Paulo Duarte, André Dreyfus, Teodoro Ramos, entre outros, brotou a idéia da criaçáo da USP. Julinho de Mesquita conquistou o apoio de seu cunhado, o então interventor federal em São Paulo, para levar adiante a idéia. Concretizou-se portanto uma vontade política que gerou um processo irreversível. Recursos financeiros foram obtidos, mas não eram vultosos. Assim, aqui se organizou a primeira universidade no País, não obstante o centro cultural brasileiro ser o Rio de Janeiro.

Estudos Avançados: Que fatores concorreram para o sucesso da iniciativa de se criar a USP e a Faculdade de Filosofia, Ciências e Letras?

Papan: Naquela época o Brasil e o mundo estavam em crise; sofríamos com a derrocada do café - a grande riqueza do País; a situação na Europa complicava-se a cada dia e náo havia perspectiva de solução; São Paulo tinha perdido no confronto com o governo central... Em contrapartida, ganhou força o interesse em se fazer alguma coisa pelo Brasil. Essa coisa principal, no meu modo de entender, foi a compreensão da necessidade de formar profissionais qualificados em determinadas árcas do saber.

A FFCL foi planejada para ser o centro da Universidade de São Paulo e teve sucesso porque para ela foram convidados diversos professores e pesquisadores estrangeiros, assim como brasileiros de alto nível.

Se ela tivesse começado somente com docentes brasileiros o fracasso teria sido total. Note-se que à época o Brasil se curvava diante da influência cultural da França. Somando todos esses fatores e a necessidade de formar-se profissionais para áreas do conhecimento em que o atraso brasileiro era incontestável, estruturou-se a Faculdade de Filosofia, cujas finalidades principais eram: preparar trabalhadores intelectuais para $o$ exercício de altas atividades culturais, de ordem desinteressada ou técnica; preparar docentes para o magistério do ensino básico e superior; realizar pesquisas nos domínios da cultura que eram o objeto de uma Faculdade de Filosofia, Ciências e Letras. 
Acentuo o detalhe de altas atividades culturais de ordem desinteressada ou técnica. Por que! Por esse dado resultar de uma velha polêmica entre ciência pura e ciência aplicada, polêmica, hoje, felizmente ultrapassada. Quando a Academia Brasileira de Ciências foi fundada, em 1916 - com o nome de Sociedade Brasileira de Ciências -, constou do primeiro estatuto que dela fariam parte apenas pessoas que estivessem envolvidas em pesquisas sem qualquer interesse prático...

Estudos Avançados: Poderia dar mais detalhes dessa velha polêmica que tem relevância para a compreensão do desenvolvimento científico no Brasil?

Pavan: O dispositivo do estatuto da SBC era uma reaçáo ao modelo de trabalho em Manguinhos - com o Oswald Cruz e o Carlos Chagas -, porque o governo se preocupava apenas com a solução de

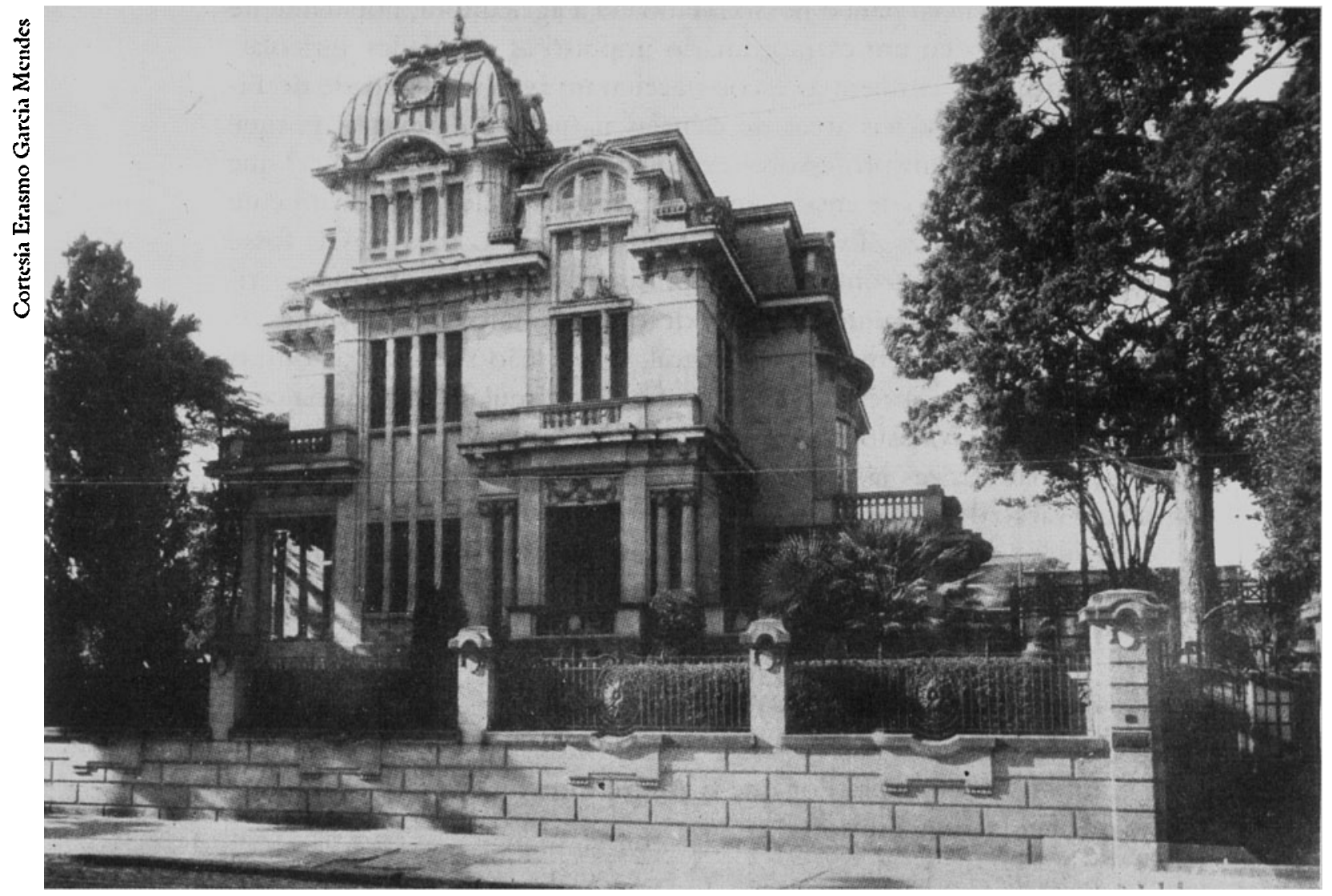

O primeiro prédio próprio da Faculdade de Filosofia, Ciências e Lctras da USP 
problemas brasileiros práticos e de interesse imediato e não entendia a necessidade de aqui desenvolvermos ciência básica. Alguns cientistas reagiram contra isso, porque acompanhavam o que se fazia na Europa. Hoje se vê que na polêmica houve incompreensôes e exageros nos dois lados. O certo é que somente se começou a dar a devida importância à ciência pura a partir de 1934, com a criaçăo da USP e da Faculdade de Filosofia.

Estudos Avanf̧ados: Antes da criação da USP já existiam em São Paulo algumas faculdades importantes, como a Medicina, Politécnica, Direito, Agronomia e outras. Isso facilitou a organização da USP? Como era a relação delas com a Faculdade de Filosofia, que foi colocada como o núcleo da USP!

Pavan: Veja o seguinte: São Paulo já tinha o Instituto Biológico e o Instituto Agronômico de Campinas que eram também muito importantes, além do Butantan. Mas, esses institutos só faziam pesquisa aplicada. O essencial para o nosso estado era a agricultura, notadamente o café e o IAC deu um extraordinário impulso às atividades agrícolas. Esses institutos e também as escolas aceitaram bem a Faculdade de Filosofia, pelo menos nas áreas de ciências naturais e de exatas, porque para a FFCL vieram professores estrangeiros muito competentes, que trouxeram novo tipo de ensino, muito diverso daquele tradicionalmente ministrado entre nós. Tal fato não teria acontecido se a FFCL fosse organizada somente com docentes brasileiros sem uma formação rigorosa. Outro dado muito relevante decorreu do fato de os docentes da FFCL dedicarem-se em tempo integral, o que não sucedia nas outras escolas, como a de Direito, ondc o professor acumulava a docência com suas atividades profissionais. Havia como exceção a Medicina, pois nela as disciplinas básicas já tinham sido estabelecidas com dedicação integral, em razão de uma exigência da Fundação Rockefeller, que financiou a construção do prédio e a vinda de professores estrangeiros.

\section{A influência de Dreyfụs}

Estudos Avanfados: Por que o André Dreyfus foi tão importante para a Faculdade de Filosofia?

Brito da Canba: A formação do Dreyfus foi na Escola de Medicina do Rio de Janeiro, na velha faculdade da Praia Vermelha. Ainda como aluno, ele ministrava um curso de Histologia aos seus colegas, para a repetição de matérias. Desde sua mocidade era um professor e, mais do 
que isso, um emérito conferencista. Quando em seu tempo, o ensino de Histologia era sem vida, estático e puramente descritivo, Dreyfus ministrava seu curso relacionando Histologia com Embriologia, Diferenciação Celular e Fisiologia. Ele associava sempre a Histologia ao funcionamento do órgão, o que é denominado de Histofisiologia. Na realidade, eu aprendi muita Fisiologia no curso dado por Dreyfus.

No Rio de Janeiro, Dreyfus teve uma relação muito estreita com pesquisadores notáveis - os irmáos Miguel e Álvaro Ozório de Almeida, e Lauro Travassos. Não podemos esquecer que ele criou dois excelentes laboratórios de Histologia - na Escola Paulista de Medicina e na Faculdade de Odontologia da USP. O Dreyfus era um produto genuinamente nacional, porque nunca estudou no Exterior.

Pavan: Vou relembrar um fato pouco conhecido. Em 1940 ou 1941, veio a São Paulo o Harry Miller Junior, da Fundaçáo Rockefeller. Visitando a Faculdade de Filoșofia, teve uma longa conversa com o Dreyfus - que era o Diretor da FFCL além de dirigir a cátedra de Biologia Geral, na qual estavam incluídos os cursos de Citologia, Histologia, Genética e Embriologia. Dreyfus transmitiu-lhe informaçōes sobre as pesquisas procedidas em seu laboratório, mas discorreu com franqueza a respeito de suas deficiências pessoais como pesquisador, em consequiência de falhas em sua formaçáo. Miller, que desde logo sentiu as possibilidades de um bom trabalho no laboratório e o indiscutível talento do Dreyfus, ofereceu a este uma bolsa de estudos nos Estados Unidos, mas com uma condiçăo - Dreyfus deveria passar lá pelo menos um ano. Dreyfus ficou muito entusiasmado com o convite, mas no dia seguinte informou ao Miller que não poderia se ausentar durante tanto tempo do laboratório. Miller disse, então, que nesse caso ele poderia substituí-lo por um professor de origem russa, que estava na Universidade de Colúmbia. Esse professor estava empenhado em fazer pesquisas na América Central. Declinou o nome - "trata-se do Theodosius Dobzhansky" . Ora, o Dreyfus ministrava seu curso baseado num livro de Dobzhansky, por isso imediatamente replicou: "Se o Dobzhansky pode vir ao Brasil, não necessito ir aos Estados Unidos". Assim, Dreyfus perdeu uma excelente oportunidade de terminar sua formação no exterior, mas, em troca, gerou um fato de incalculável significado para o desenvolvimento da Genética no Brasil.

Brito da Cunba: Dreyfus foi um excelente diretor da Faculdade de Filosofia. Com apoio da Fundação Rockefeller e do Fundo de Pesquisa da USP trouxe professores de renome e muito competentes, como os matemáticos Zarisky e André Weil, que aqui passaram um ano. Mas, 
como diretor da Faculdade, naturalmente, teve de diminuir sua atividade como responsável pelo Departamento de Biologia.

De origem judaica, Dreyfus era um agnóstico. Como incentivou a vinda para USP de cientistas europeus, muitos dos quais de origem judaica, contra ele em certa época propalou-se a idéia de que era preconceituoso. Acusação improcedente porque Dreyfus apenas considerava o valor científico de cada um dos professores convidados para a USP. Também chegou a ser considerado como macarthista, pelo fato de ter atacado e desmascarado o charlatanismo das teorias de Lysenko. Ora, os fatos demonstraram como Dreyfus estava absolutamente certo, pois, afinal, Lysenko contribuiu para destruir a Genética na Uniăo Soviética. Dreyfus era um liberal e acima de tudo empenhava-se em impulsionar o trabalho científico no Brasil.

Dreyfus montou uma boa estrutura no Departamento de Biologia. Trouxe uma excelente pesquisadọra técnica de origem alemã, a Marta Erps Breuer, que havia estudado e trabalhado no Bauhaus e lá convivido com personalidades mundialmente famosas, como Gropius, Kandinsky, Klee etc. Entre outros, também trabalharam no início de nosso laboratório Gualberto Evangelista Nogueira, Henrique Serafim de Oliveira, Anita Schell, Cândida de Paula Souza e Waldemar de Oliveira, logo seguidos por Therezinha Moraes Ungaretti, Pedro Monteiro e Gabriel do Prado Bueno.

Dreyfus era uma pessoa de interesses muito amplos. Gostava de música, teatro, cinema, boa comida e bons vinhos e era demasiadamente generoso. Aos sábados levava seus assistentes para almoçar com ele em restaurantes. Eram também convidados pessoas como Zeferino Vaz, Edmundo Vasconcelos, Edgard Barrozo do Amaral, Nelson Planet Buarque entre outros.

Quando, em 1948, descobriu que tinha um grave problema de hipertensáo, mudou de vida, privando-se de quase tudo de que gostava, a fim de ter a possibilidade de reunir recursos para um Premio de Genética, no valor de mil contos de réis - um dinheirão para a época. Esse prêmio foi dado por duas vezes e, depois, essa fortuna evaporou-se com a inflação.

O Dreyfus foi assim e seu maior prazer era transmitir conhecimentos a seus alunos, a seus amigos e às pessoas com quem convivia: engraxates, barbeiros, ascensoristas e garçons. Sempre tinha em torno de si uma boa audiência e a todos dava, quotidianamente, aulas extraordinárias de vida... 


\section{Os cursos de ciências}

Estudos Avançados: Qual a contribuição dos professores estrangeiros de ciências na Faculdade de Filosofia?

Pavan: Na Física, houve a notável contribuiçăo de Gleb Wataghin e de Giuseppe Occhialini. Na Química, tivemos Heinrich Rheinboldt, primeiro e, depois, Heinrich Hauptmann. Na Botânica, o mestre foi Felix Rawitscher, posteriormente seguido por Mário Guimarães Ferri. $\mathrm{Na}$ Zoologia, inicialmente Ernest Bresslau, que logo morreu, sendo substituído por Ernest Marcus. Na Genética, naturalmente, aprendemos com Dreyfus. Na Paleontologia, Ottorino De Fiori e, posteriormente, Victor Leinz. A Mineralogia esteve a cargo de Ettore Onorato.

Wataghin propiciou extraordinário desenvolvimento da Física, porque, além da sua competência, estimulava os alunos, que depois se destacaram bastante. Na Química, Rheinboldt nos deu uma base fundamental muito boa, o que permitiu a seus alunos especializarem-se em várias áreas $\mathrm{e}$ posteriormente trabalharem $\mathrm{em}$ indúsirias importantes. $\mathrm{Na}$ Matemática, ministravam cursos Luigi Fantappié e Giácomo Albanese, porém o maior desenvolvimento dessa área ocorreu um pouco depois. Resumindo, o que vejo de mais importante na experiência desses professores estrangeiros - que vieram para a FFCL - é terem eles contribuído para o aggiornamento e a modernização da Ciência no Brasil.

É interessante assinalar os estreitos contatos existentes à época entre biólogos, físicos e químicos de instituiçōes diferentes, o que hoje só raramente acontece. É certo terem sido esses contatos, depois, incentivados pela Sociedade Brasileira para o Progresso da Ciência. Relembro, ainda, com grande satisfação, os frequientes encontros que ocorriam entre pessoas de áreas diferentes nos corredores das dependências da FFCL.

Estudos Apançados: Por que, naquela fase inicial, a Faculdade de Filosofia foi táo importante dentro da USP? Por que, de certa forma, sua influência decaiu?

Papan: A Faculdade de Filosofia, Ciências e Letras era muito respeitada. Isso provocava ciumeiras nas outras faculdades. Seu grande prestígio decorria do alto nível de seu ensino e do valor científico de suas pesquisas. Mas, aquela competiçăo dentro da USP, afinal de contas, era salutar.

O fato básico era que na Faculdade de Filosofia havia a integraçáo 
das áreas científicas. Nas reuniōes da Congregação, e fora dela, a troca de idéias era formidável, pois todos queríamos saber o que os professores de outras áreas pensavam e faziam.

A maioria dos professores ministrava muitas aulas e parece até que tinham prazer nisso. Refiro-me especialmente a Dreyfus, Marcus, Rawitscher, De Fiori e Onorato. A maioria dos professores tinha grande sobrecarga didática até a formação de seus discípulos, com quem passavam a repartir seus trabalhos. De outro lado, era extraordinário o interesse dos professores e alunos pelos cursos. Aí está uma das causas do sucesso da Faculdade de Filosofia naquela fase. Atribuo a queda de sua influência à saída dos cursos de ciências naturais e exatas. Pois quando nela esses cursos eram ministrados, seu prestígio intelectual batia de longe o da maioria das escolas profissionais.

Estudos Avanfados: Como foi o apoio da Fundaçăo Rockefeller à Faculdade de Filosofia e a outras faculdades da USP?

Pavan: A Fundação Rockefeller possuía um programa amplo de apoio ao desenvolvimento científico em diversos países. Ela dava um auxílio determinado para projetos específicos. Foi o que sucedeu com a Faculdade de Medicina, na década de 20 . Forneceu recursos para a construção do prédio e pagamento de professores com dedicação integral. Possibilitou, igualmente, a vinda de professores estrangeiros, como o Alfonso Bovero. Com a eclosão da II Guerra Mundial, a Fundação suspendeu seus trabalhos na Europa e na Ásia, concentrando-se na América Latina. Por isso, a partir de 1942 , no Brasil, começamos a receber uma grande ajuda e, para tanto, foi excépcional a atuaçâo de seu representante na América do Sul, Harry M. Miller Júnior.

A Rockefeller deu importante apoio à Saúde Pública, auxiliando muito a entáo Faculdade de Higiene. Quanto à Faculdade de Filosofia, a Fundaçáo concedeu-nos recursos para diversos projetos de pesquisa, para equipamentos e até mesmo para a importação de automóveis para os trabalhos de campo. Náo pagava o pessoal, mesmo porque os cursos náo necessitavam de tanto dinheiro, pois as turmas eram pequenas uma dúzia de alunos e, às vezes, até menos. Para esse tipo de despesa, os recursos da USP eram suficientes.

Durante vinte anos a Fundação Rockefeller ajudou o Departamento de Biologia, mas nunca interferiu na orientação de nossas pesquisas. Apenas, tínhamos a obrigaçáo de prestar um relatório oral ao Miller e esse táo somente fazia comentários, informando também sobre o que se pesquisava em outros laboratórios. Na verdade, ele propiciava vários tipos de colaboração e de intercâmbio de nossa comunidade com 
a de outros centros de pesquisa no Brasil e no exterior. E Miller podia dar uma contribuição valiosa porque tinha boa formaçáo universitária, por ter sido docente de Parasitologia, além de ser muito bem informado sobre as pesquisas em andamento em vários países. Ele náo só ajudou a Genética, mas a outras áreas científicas. No passado foram veiculadas acusações levianas contra a Fundaçáo Rockefeller, chegando-se até a afirmar que ela agia contra os interesses do Brasil. Nunca concordei com tais afirmaçóes, pois acompanhei de perto suas atividades durante muitos anos.

\section{Dobzhansky no Brasil}

Estudos Avanfados: Como foi a passagem de Dobzhansky pela Faculdade de Filosofia? Por que sua presença foi decisiva para a evolução da Genética no Brasil?

Pavan: Dobzhansky veio a São Paulo e ao Brasil, pela primeira vez, em 1943. Seu plano era dar algumas poucas aulas e coletar drosófilas, mas essas aulas transformaram-se num curso memorável. Foram assistidas por um público de cerca de 100 pessoas que lotava o auditório da Química. Dobzhansky escrevia os textos em inglês, os quais eram traduzidos pelo Dreyfus. Pouco a pouco ele foi aprendendo o português e eu e o Brito da Cunha corrigíamos sua pronúncia. Todos os biólogos importantes de São Paulo acompanharam as suas conferências, como Carlos Arnaldo Krug e Alcides de Carvalho, de Campinas; Friedrich Brieger e seus assistentes, de Piracicaba; Zeferino Vaz e João Veiga, da Veterinária; os pesquisadores do Instituto Biológico e do Instituto Butantan e alguns colegas da Medicina. Naquelas aulas o difícil era conseguir um lugar no auditório...

Um fato chamou a atenção: o comportamento do Dreyfus. Mais parecia um aluno e simples tradutor, quando era um mestre em Genética e conhecia o livro básico de Dobzhansky. Na verdade, já muito famoso como biólogo, ele entregou o laboratório nas máos do Dobzhansky e se tornou o maior propagandista do curso do professor visitante. Naquela primeira vez em que esteve aqui, Dobzhansky ficou cerca de 100 dias, entre os quais, um mês em Belém do Pará coletando material. Nos anos seguintes veio outras vezes ao Brasil, sendo que por duas vezes permaneceu por mais de um ano. Sempre nos auxiliando, discutindo nossos projetos, transmitindo experiências.

Brito da Cunba: Dobzhansky ensinou-nos uma coisa básica: que deveríamos concentrar nosso trabalho em problemas da natureza do 
Brasil. Era o mesmo ponto de vista do Rawitscher, que, dando o exemplo, iniciou as pesquisas sobre a regiáo dos cerrados, considerada até então como inviável para a produção agrícola. Hoje muito se fala na pujança da agricultura nos cerrados, mas poucos sabem que foram os trabalhos de Rawitscher, Mário Guimarães Ferri e seus colaboradores que abriram caminho para se utilizar essa enorme parcela do território nacional.

Dobzhansky gostava de viajar e esteve em diversos países, mas em nenhum outro ele obteve tanto sucesso como aqui, em nenhum outro lugar ele teve um papel tão importante como o que desempenhou para a evolução da Genética no Brasil.

Dobzhansky desde jovem - quando leu as narrações de viagens de naturalistas que passaram pelo Brasil, como Darwin - sempre desejou conhecer as florestas brasileiras. Quando veio para cá, organizou viagens pelos mais diversos pontos de nosso país. Para tanto, utilizamos os mais variados meios de transporte e ele não se preocupava com as condiçōes de hospedagem. Por isso, com freqüência, dormia em casebres, redes e até mesmo em grutas. Nesse vasto trabalho de coleta de materiais tivemos um apoio valiosíssimo - o do Correio Aéreo Nacional, da FAB, graças à interferência de um irmão do Pavan, o brigadeiro Clóvis Pavan. Naquela época, o Correio Aéreo era a única forma de o governo federal assistir a comunidades isoladas nas perdidas paragens do Norte e do Centro-Oeste. Assim, os velhos DC3 da FAB também foram muito úteis para Dobzhansky e seus colaboradores do Departamento de Biologia. Coletamos drosófilas em mais de 70 lugares - desde a Flórida até Buenos Aires.

Estudos Avançados: Naquela fase não existiam agências como $\mathrm{CNPq}$, Finep, Fapesp etc. Além da Fundaçăo Rockefeller, quais órgāos e pessoas auxiliavam financeiramente as pesquisas?

Pavan: O Professor Jorge Americano - que foi um excelente Reitor da USP - criou um Fundo de Pesquisa da Universidade. Esse fundo financiou alguns projetos de pesquisa, entre os quais um, desenvolvido pelos físicos - a fabricação de sonares, indispensáveis à defesa contra os submarinos. Alguns empresários sempre nos auxiliavam quando a eles recorríamos. Cito alguns exemplos: Cícero Prado, Francisco Pignatari Filho, Américo e Angela Capone, entre outros. Os trabalhos de sistemática e a classificação de drosófilas foram publicados graças a eles. Ademais, muitos trabalhos foram efetuados porque o Dreyfus pessoalmente pagava as despesas, com dinheiro de seu salário. 


\section{O laboratório da Glete}

Estudos Avançados: O laboratório de Biologia na alameda Glete é hoje uma lenda. Com que recursos contava e como, nele, eram orientadas as pesquisas?

Pavan: Como catedrático, Dreyfus decidia sobre a orientação, mas sempre levava em boa conta a opiniáo dos assistentes. Recordo-me de uma decisão sábia e que marcou o rumo de nossas pesquisas. Foi a de concentrarmo-nos, todos nós, no estudo de drosófilas, abandonando projetos individuais de pesquisas. Essa orientação teve total apoio do Dobzhansky. Passados tantos anos, creio ter estado nisso - evitar a dispersáo de esforços e recursos - uma das razóes que nos conduziram ao sucesso e prestígio internacional dado ao Departamento.

Antes de nosso contato com a Fundação Rockefeller, não era fácil conseguirmos recursos financeiros para as viagens com a finalidade de coletar material. Por razóes injustas, tāo freqüentes no funcionalismo, alguns de nós ganhavam pouco. Por isso dividíamos nossos salários, para dar uma complementação aos que recebiam remuneração mais baixa. No laboratório havia a crença de que fazíamos realmente um trabalho muito importante. Entre o pessoal, desde os serventes, o relacionamento era como em uma grande família unida. Solteiro, Dreyfus fez desse pessoal a sua família. Almoçávamos no laboratório e não havia horário de trabalho, pois, com freqüência, pesquisávamos até a meianoite.

Brito da Cunha: O Departamento ficava no sótáo de um casarão na alameda Glete, que hoje não mais existe e havia pertencido ao industrial Jorge Street. Esse sótáo servia anteriormente como o alojamento destinado aos serviçais do antigo proprietário. Pavan montou uma laje no telhado, para lá construir um tanque adequado à sua pesquisa com peixes. Para dar ao Dobzhansky um local de trabalho foi feita uma escavaçáo no poráo. Nesse subsolo, insalubre e apertado, ele passava dias pesquisando conosco, acompanhado por sua esposa. Esse era o famoso laboratório, mas nunca entre nós houve quaisquer reclamaçóes ou protestos por falta de comodidade.

Estudos Apanf̧ados: Na Genética, qual o relacionamento da Faculdade de Filosofia com as outras instituiçóes de pesquisa?

Papan: Essa atividade começou com o Dreyfus. Freqüentemente ele nos levava ao Agronômico e à ESALQ. Com o Dobzhansky esse relacionamento tornou-se mais constante. Penso que a Genética no Bra- 
sil começou em 1943 - tendo como centro o Dobzhansky e como pedras fundamentais Dreyfus, Krug, Briger e o Harry Miller, da Fundação Rockefeller. Esses cinco foram a base que verdadeiramente ergueu a Genética entre nós - hoje internacionalmente muito respeitada.

Brito da Cunba: Com a chegada do Dobzhansky, passou a haver um intercâmbio permanente de nosso laboratório com os do IAC e da ESALQ. Coordenada pelo Dobzhansky, em 1943 organizamos a primeira Conferência Nacional de Genética, em Piracicaba.

A partir de 1948 começamos a trazer geneticistas de outros laboratórios: Hans Burla, Chana Malagolowkin e Antonio L. Cavalcanti, do Rio; Marta Wedel, da Argentina; L.C. Birch, da Austrália, que deu o primeiro curso de ecologia animal no Brasil; Bruno Battaglia, da Itália; Ove Frydenberg, da Dinamarca; A.R. Cordeiro, de Porto Alegre; Danko Brncic, do Chile; W.L. Carson, dos Estados Unidos; F.M. Salzano, de Porto Alegre e diversos outros. Além disso, fazíamos muitas viagens, coletando drosófilas em todas regiōes de interesse ecológico. Esse intenso intercâmbio científico foi possível devido ao apoio financeiro da Fundação Rockefeller, que também forneceu bolsas para estudarmos nos Estados Unidos. Lá estivemos Pavan, Freire-Maia, FrotaPessoa, Salzano, W. Kerr, Antonio Rodrigues Cordeiro, Antonio Lagden Cavalcanti, Almiro Blumenschein e eu, entre outros.

Estudos Avanfados: O trabalho dos geneticistas da Faculdade de Filosofia foi se integrando num círculo mais amplo, dentro e fora do Brasil?

Pavan: Sim, nosso trabalho se espraiou além das fronteiras da alameda Glete. Logo passamos a contar com a colaboração de colegas de América Latina, Estados Unidos, Europa e Austrália. Laços estreitos foram estabelecidos entre os pesquisadores em Genética. Numa primeira etapa, no Brasil, pesquisamos drosófilas mas, depois, enfrentamos outros desafios. Diversos geneticistas, que :iveram bolsas em São Paulo e nos Estados Unidos, voltaram para seus pontos de origem e lá criaram bons laboratórios. Mas sempre mantivemos entre nós um intercâmbio permanente. Uma das conseqüências desse procedimento foi a criaçáo, em 1955, da Sociedade Brasileira de Genética, que edita atualmente uma excelente revista.

Estudos Avançados: Que publicaçōes foram editadas e como é conservada a memória do Departamento de Biologia da Faculdade de Filosofia? 
Brito da Cunha: A maioria de nossos trabalhos foi publicada no Exterior. Também publicamos muitos outros no Boletim da Faculdade de Filosofia. Os documentos sobre essas atividades estáo no Departamento de Biologia do Instituto de Biociências da USP. Infelizmente, até hoje não conseguimos um espaço para organizar essa documentaçăo, a fim de abri-la para o público. Esse é um problema que não é só da Biologia. A única exceção é o museu e o arquivo da Faculdade de Medicina, organizados exemplarmente pelo Carlos da Silva Lacaz.

\section{O modelo da Sorbonne}

Estudos Avançados: Professor Erasmo, como analisa a fase inicial da Faculdade de Filosofia, Ciências e Letras nas áreas de ciências?

Erasmo Garcia Mendes: No final dos anos 20 e começo dos 30, a formação universitária que dava status era $\mathrm{em}$ Medicina, Engenharia e Direito. Meu pai era médico e homem apreciador da cultura francesa. Assim, em minha casa, falava-se muito no papel das universidades, em especial da Sorbonne. Desse modo, quando foi criada a FFCL, percebi que estava surgindo em São Paulo alguma coisa nos moldes da universidade francesa. Então, com o meu amigo Lourival Gomes Machado, decidimos entrar nessa Faculdade, nas secçōes da mesma condizentes com nossas inclinaçóes. Lourival em Ciências Sociais, eu em História Natural. Graduados, ambos permanecemos na FFCL, na qual fizemos nossas carreiras universitárias.

Ingressei na FFCL em 1936, mas, naquele ano, não pude estudar, pois não havia curso noturno e eu precisava trabalhar para meu sustento. Vivia de aulas particulares e de um emprego público. Retornei à Faculdade em $1937 \mathrm{e}$, nessa ocasião, graças à compreensáo de todos professores, sobretudo Ernest Marcus e Paulo Sawaya, que me asseguravam a frequiência, e à solidariedade de colegas que me emprestavam livros e apontamentos, pude passar de ano. Em 1938, finalmente, cessaram as dificuldades quando os citados professores arranjaram-me uma monitoria remunerada no Departamento de Zoologia. Assim começou minha carreira universitária.

Estudos Avançados: Como era o curso de ciências naturais?

Erasmo: Originalmente, de forma inadequada o curso chamava-se Ciências Naturais, na intenção de abranger da Física à Biologia. Assim, em meu diploma consta que sou bacharel em ciéncias naturais, mas, quando fiz a complementação didática, o curso já outorgava o título de 
licenciado em História Natural, e era composto de dois setores: o biológico e o geológico.

Ao ingressar na FFCL, a minha impressão foi de deslumbramento pela forma como nela se transmitia o saber, tão distante da rotina tradicional de outras faculdades. As aulas náo se limitavam às matérias relacionadas com a Biologia e a Geologia, pois as liçóes sempre continham elementos de Filosofia de Ciências e de História. Outra causa desse deslumbramento resultava da presença de professores estrangeiros, todos muito competentes, sempre dispostos a esclarecer - em palestras ou conversas informais - pontos que tivessem ficado obscuros. Aliás, freqüentemente as conversas tinham lugar na casa dos próprios mestres, pois as turmas eram pequenas e permitiam o convite. Por outro lado, o caráter multiforme da FFCL propiciava o contato com professores e alunos de outras áreas do saber e tínhamos a oportunidade de ouvir palestras e ver nos corredores da Faculdade elementos que iriam se projetar no cenário cultural mundial, como Lévi-Strauss, Braudel, Wataghin, Occhialini e outros. Na minha própria secção, surpreendi-me nas aulas práticas de Botânica, vendo, ao meu lado, debruçado sobre o microscópio, esse extraordinário cientista que foi Rocha Lima (um dos fundadores da USP), modestamente fazendo uso da instituição que ajudara a criar, como simples aluno voluntário. A gente se sentia estimulado em ter ao lado o homem que fora agraciado pelo governo alemáo por haver esclarecido a natureza e debelado o surto de tifo exantemático no exército, durante a Primeira Guerra Mundial.

No curso de História Natural, ao lado das disciplinas diretamente ligadas à Biologia e à Geologia, havia matérias complementares, como Física e Química. Quem se encarregava desta última era o Prof. Heinrich Hauptman, ainda jovem, que tinha sido assistente de Windaus, na Alemanha. Acompanhando o Prof. Ernest Bresslau (primeiro contratado para Zoologia, falecido em 1935), veio ao Brasil, como assistente técnica, Gertrud Siegel, a qual representava, para nosso meio, um tipo novo de colaborador dos catedráticos. Cito esse exemplo para assinalar ter sido quase uma norma esses professores virem acompanhados pelos seus técnicos, que os seguiam mesmo quando emigravam para outros países. Gertrud era uma pessoa culta e, como dominava o alemão, foi de grande valia na traduçáo de textos e de protocolos experimentais, nessa língua, para as aulas teóricas e práticas de Zoologia e Fisiologia.

Estudos Avanfados: Qual a sua recordação dos professores da primeira fase da Faculdade de Filosofia? 
Erasmo: No meu curso, desde logo optei pelas disciplinas de Zoologia e Fisiologia animal. Os mestres que mais me seduziam eram o Prof. Ernest Marcus, sucessor de Bresslau e o Prof. Paulo Sawaya. Marcus foi um dos melhores zoólogos deste século e, na Alemanha, antes de se tornar titular, fora assistente de Hesse e Heider na Universidade de Berlim. Veio ao Brasil acompanhado de sua esposa, Eveline Du Bois Reymond Marcus, também zoóloga de renome e pertencente a uma tradicional família de biólogos, entre os quais seu avô, Du Bois Reymond, um dos fundadores da Fisiologia moderna. Mas outros professores estrangeiros também impressionavam vivamente. O Prof. Felix K. Rawitscher era um notável botânico e acabou por instalar, no Brasil, a pesquisa de cunho ecológico, ao estudar os cerrados. Outro notável estrangeiro foi o Prof. Ettore Onorato, ex-aluno de Bragg, eminente mineralogista, especializado em cristalografia. $O$ seu primeiro assistente nacional foi o Prof. R. Saldanha da Gama, que o sucedeu quando retornou à Itália. Da Paleontologia e da Geologia estava encarregado outro italiano, o Barão Ottorino De Fiore, um siciliano altamente versado em suas especialidades (era inclusive malacólogo e vulcanólogo). Onorato e De Fiori ministravam aulas em italiano: Rawitscher e Marcus, que tinham intenção de permanecer no País, logo aprenderam um excelente português.

Quanto aos professores brasileiros que foram aproveitados pela seç̧ão de História Natural da FFCL, cumpre destacar André Dreyfus, sobre o qual Pavan e Brito da Cunha já falaram, ressaltando seus méritos como professor, cientista e cultor das artes e literatura. Era também um excelente didata. O Prof. Paulo Sawaya, de quem, ao me formar, tornei-me assistente, era médico e iniciou sua carreira de biólogo como anatomista na Faculdade de Medicina de São Paulo. Mas, desde cedo, mostrou-se um apaixonado pela Zoologia. Essa paixáo levou-o a ser o primeiro assistente de Bresslau e, posteriormente, catedrático da Fisiologia geral e animal da FFCL, disciplina que se ocupava dos aspectos comparativos das funçōes na escala animal. Dreyfus veio a São Paulo, provavelmente trazido por Rocha Lima, para ser assistente de Histologia na Faculdade de Medicina. Sua paixão pela Genética e, de forma geral, pela Biologia, acabou também por conduzi-lo à FFCL, na qual encontraria campo para se desenvolver. Náo foi o único carioca (na verdade, era gaúcho de Pelotas) atraído pelo surto cultural que ocorria em São Paulo. Rocha Lima também fez vir do Rio, ao que me parece, M. Rocha e Silva, J. Reis, A. Martins Penha e, talvez, Paulo Galvão para o Instituto Biológico, onde, como diretor, substituiu Arthur Neiva.

Estudos Apanf̧ados: Como uma escola recém-criada, nos anos 30, onde funcionaram os departamentos da Faculdade de Filosofia? 


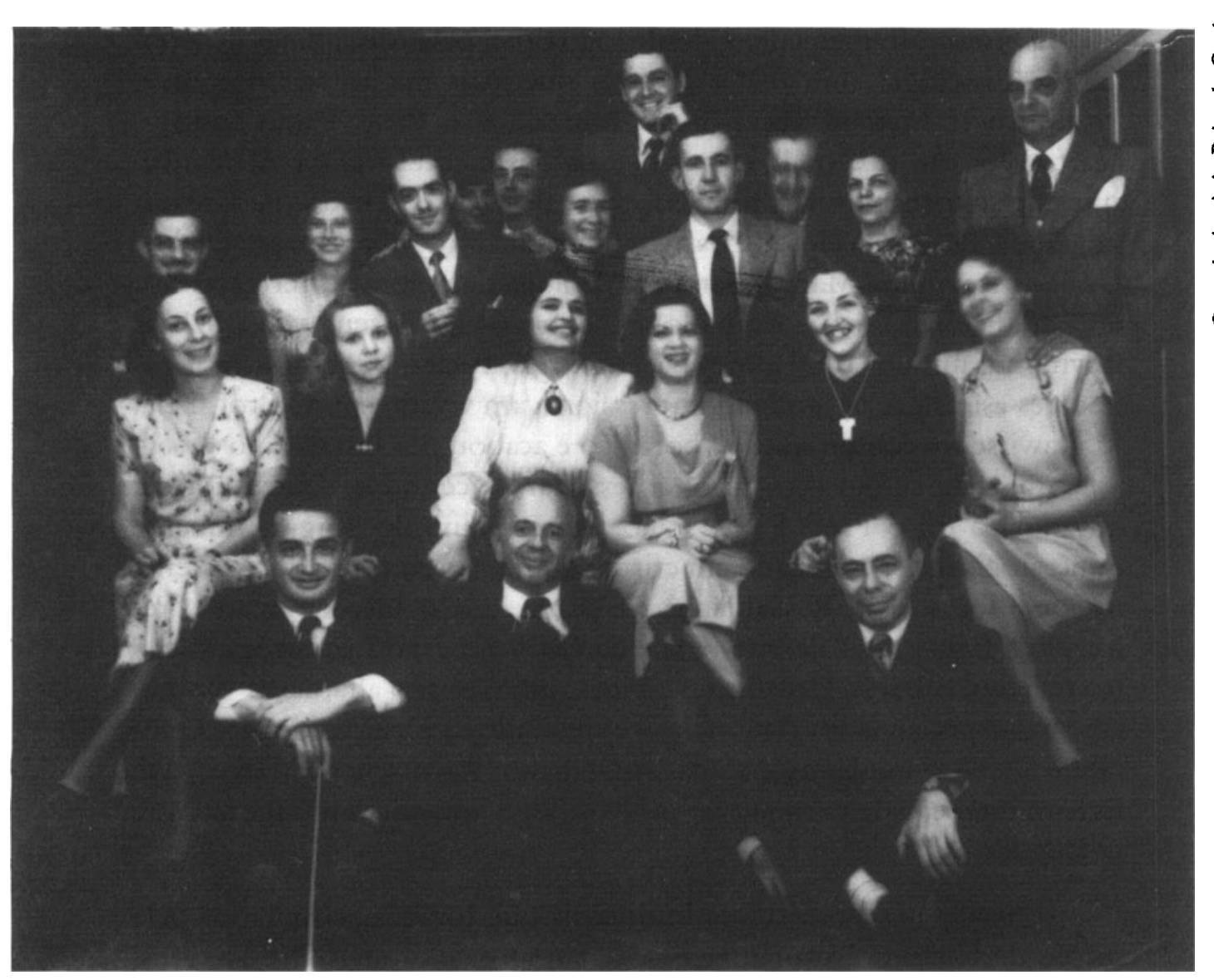

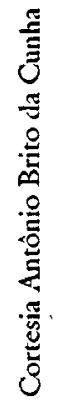

Pesquisadores do Departamento de Biologia da FFCL-USP, em 1948

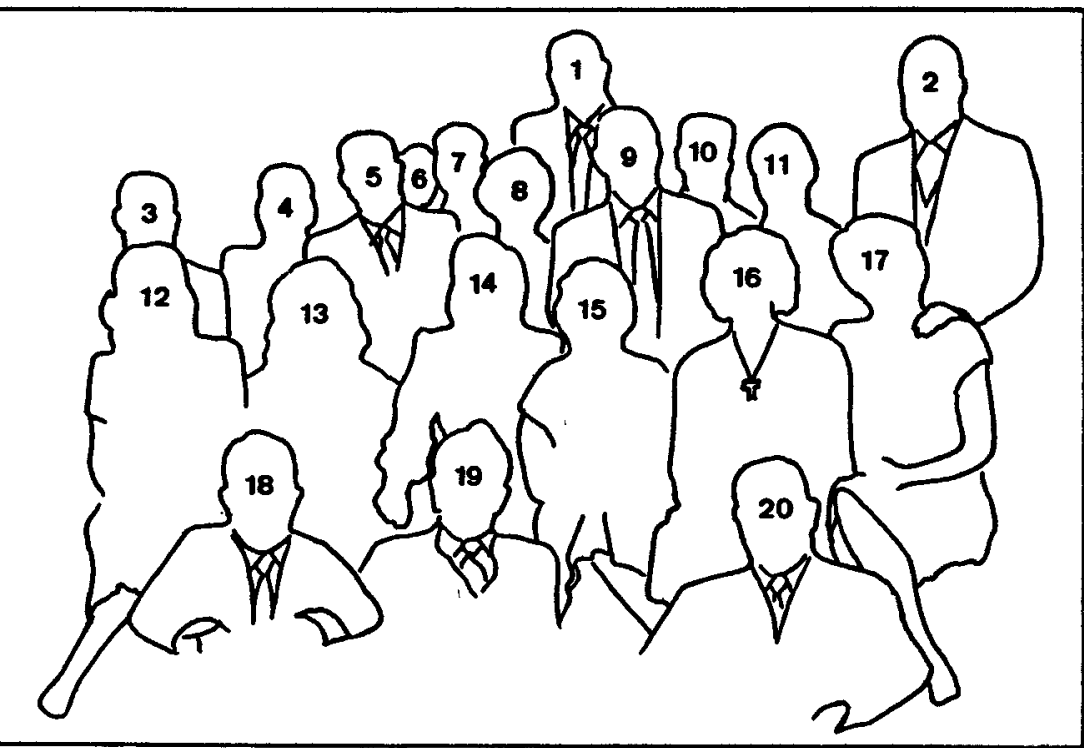

Antônio Rodrigues Cordeiro (1), Otávio Vaz de Oliveira (2), Mário Ferri (3), Lygia Brito da Cunba (4), António Brito da Cunba (5), Flávia Maia (6), Newton Freire Maia (7), Anita Nickele (8), Hans Burla (9), António Cavalcanti (10), Candida de Paula Souza (11), Marta Wedel (12), Ruth Ferri (13), Maria de Loures Pavan (14), Inah Cavalcanti (15), Malvina Cordeiro (16), Chana Malogolowkin (17), Crodowaldo Pavan (18), Theodosius Dobzhansky (19) e André Dreyfus (20). 
Erasmo: Quanda de sua fundação, a FFCL não recebeu qualquer prédio para alojar seus departamentos. Esses foram instalados, em sua grande maioria, nos espaços ociosos da Faculdade de Medicina. O Departamento de Física ficou, se não me engano, na Escola Politécnica; o de Matemática, numa casa na rua Alfredo Ellis. Náo tardaram a surgir problemas no caso da Faculdade de Medicina, que culminaram quando houve a intenção, inicialmente materializada, de ampliar o Departamento de Química numa das alas do prédio da Dr. Arnaldo, ocasiáo na qual os alunos, principalmente, se insurgiram contra o que lhes pareccu um passo no sentido de tornar permanente a FFCL na FM e uma desfiguração do belo prédio, estilo Tudor, no qual se abrigava. Houve depredação das obras em andamento, tendo ficado patente que a situação não podia continuar.

Os primeiros departamentos a saírem da FM foram os que independiam de laboratórios, logo, os de Filosofia, Ciências Sociais e Letras, alojando-se em um casaráo pertencente ao Emb. Macedo Soares, no local onde posteriormente se ergueu a Biblioteca Municipal. Daí, essas secçóes transferiram-se para o terceiro andar da Escola Caetano de Campos e, finalmente, para a histórica Maria Antonia. Os Departamentos de Química e de História Natural ainda ficaram algum tempo na FM, até serem transferidos para um edifício localizado na esquina da alameda Glete com Guaianases. Nesse local estava o elegante prédio, ex-residência do industrial Jorge Street. Nele, instalaram-se a Mineralogia \& Petrografia, a Zoologia \& Fisiologia, a Biologia Geral. Na enorme edícula ficou a Botânica e, para a Química, foi construído prédio especial, no espaço vazio do terreno. Estávamos entre 1937 e 1938. Não será preciso dizer que a instalação de tantos departamentos nas dependências do velho Street, acabou por desfigurar essa residência de grande beleza arquitetônica, convertendo-a numa espécie de cortif̧o científico. Aí ficamos até 1955 , quando começou a mudança para a Cidade Universitária. O palacete da Glete, juntamente com o prédio da Química, foram demolidos e, no local, resta (ou restou?) talvez uma centenária figueira que, em um dia da Árvore, fora tombada pelo Município, na presença do diretor da FFCL, o saudoso Eurípedes Simóes de Paula.

\section{Fantappié salvou a FFLC}

Estudos Avançados: Como foi a tentativa de se acabar com a Faculdade de Filosofia em 1938?

Erasmo: A FFCL foi idealizada por Júlio Mesquita Filho, no con- 
texto da Universidade de São Paulo. De 1932 e 1937 houve forte disputa política em Sáo Paulo, entre o Partido Constitucionalista (sucessor do Partido Democrático) e o velho Partido Republicano Paulista (PRP), que estiveram transitoriamente unidos na Revoluçăo de 32 , mas logo se antagonizaram após a derrota. Com a eleiçáo de Armando de Salles Oliveira, do PC, em 1934, a situação pendeu para esse partido, sendo o governador cunhado de J. Mesquita Filho. Essa circunstância permitiu a criação da USP, logo tida pelo PRP como criaçáo do partido inimigo. Assim, inaceitável. Com a implantaçăo do Estado Novo, em 1937, Armando teve de sé exilar e o interventor nomeado para São Paulo foi Adhemar de Barros, após breve gestáo de Cardozo de Mello Neto. Adhemar pertencia ao PRP e, por isso, náo via com bons olhos a criação de Armando, isto é, a FFCL. Nisso era acompanhado por outros setores da sociedade conservadora, entre os quais a Igreja, que julgava cssa faculdade um antro de ateísmo. Também porque o contrato de professores estrangeiros para a mesma frustrara a pretensão dos nacionais, que se consideravam aptos a encarregarem-se do ensino e pesquisa em disciplinas inteiramente novas no nível superior, tais como Filosofia, Ciências Básicas e Letras. Assim, a campanha movida por interesses religiosos, políticos ou subalternos chegou a tal vulto que houve a intençăo, por parte do governo, de extinguir a FFCL. Essa intenção quase chegou a ser concretizada quando, em uma manhã, do ano de 1938 se não mie engano, o Conselho Universitário da USP reuniu-se na Faculdade de Direito para discutir a questáo. Para essa reunião foram convidados os Profs. Marcus e Luigi Fantappié. A proposta de se destruir a FFCL só não teve êxito porque, segundo me contou o Prof. Marcus, Fantappié emudeceu os conselheiros com uma brilhante defesa dos objetivos da Faculdade, mostrando que sua extinção seria um inconcebível retrocesso em termos culturais e científicos. Assim, o grande matemático italiano salvou a FFCL

Sempre me perguntei por que chegou do Conselho Universitário a cogitar dessa extinção. É mera presunção minha que a reuniăo deveu-se à passagem pela diretoria da FFCL do Prof. Alexandre Corrêa, expoente de filosofia escolástica entre nós e, por isso, julgado pelo governo estadual como adequado ao triste papel de algoz da Faculdade. Mas o governo não contou com a hombridade e a lisura de Alexandre Corrêa, que, inteirando-se da seriedade de propósitos da FFCL, não se prestou ao sórdido papel e teria propiciado a reunião do Conselho Universitário, demitindo-se a seguir. Mas o governo não se conformou. Impos como diretor da Faculdade um pesquisador da história paulista, perrepista de quatro costados, Alfredo Ellis Jr. Deu-se de novo mal o governo. Em 
pouco tempo Ellis foi inteiramente cativado pela Faculdade e acabou se tornando catedrático da mesma. Esse episódio da reunião do Conselho Universitário, a meu ver, não teve a repercussão desejada e parece ter caído no olvido. Caberia consulta às atas do Conselho (se é que no caso houve ata) para precisar data e detalhes dos debates. É obra para historiador. 